\title{
Semantic Bypassing in Technical Communication: The Historical Case of Antiseptics
}

\author{
Jennifer J. Connor \\ J.T.H. Connor \\ McMaster University
}

Although problems resulting from ambiguity in technical discourse are generally recognized, few studies provide examples of actual instances. Specifically, the problem known as bypassing has not been fully explored. This paper therefore examines an important historical example, the medical term antiseptics, to show the impact that bypassing can have on communication of technical information. The term antiseptics was in use for over 150 years before Joseph Lister adopted it in the 1860s to describe his new system of surgical treatment. A review of published responses of Canadian doctors to Lister's writings indicates that confision arose owing to the fundamentally different perceptions of the term for Lister and his audience.

A WRITER MAY INTENTIONALLY USE AMBIGUITY to enhance a literary work (Empson, 1961). But when a writer needs to convey information for the reader to act upon-as in technical communication-ambiguity becomes a barrier to communication, a barrier usually identified as a semantic one since it involves the meanings of words. This semantic barrier has been described in various ways, from Alfred Korzybski (1958) to Samuel Hayakawa, who described it more concretely as "the consciousness of similarities, but not of differences"(1972, p.230). Historian David Fischer referred to the "fallacy of ambiguity," noting that it could occur when a writer uses an old term in a new way without warning (1970, p.265-266).

O 1988 IEEE. Reprinted, with permission, from IEEE Transactions on Professional Communication, Vol. 31, No. 1, 13-17, March 1988. 
Yet, simply to say that a term is ambiguous or shows "consciousness of similarities rather than differences" does not conveniently capture the full sense of the barrier. Another term, bypassing, does depict the problem vividly. In explaining this term, William V. Haney noted that its immediate consequences include apparent agreement, where individuals feel they have understood one another, and apparent disagreement, where actual agreement is concealed by their choice of words (1979). Haney's term is useful for technical communicators since it succinctly conveys both the type of barrier and its effect on the intended communication: in essence, meanings are "bypassed" in the minds of two people who attempt to communicate.

Haney was interested in semantic considerations in business communication and provided anecdotal, organizational, and political examples to illustrate the consequences of bypassing. Other business communicators have provided similar brief or general examples that often are so abstract or simplistic that they are ineffective as illustrations (Lewis, 1980; Lee, 1982; Weeks, Jameson and Gieselman, 1984). To date, however, with the exception of brief reference to distortion caused by changes in meaning between writer and reader of computer texts (Hunt and Kirkman, 1986), little has been written specifically on the topic by technical communicators. Current work on semantics in the field focuses more on the use of metaphor (Chisholm, 1986; Butler, 1986).

To know more about the context of the problem in science, however, we can turn to sociologists and philosophers of science who have studied technical and scientific discourse. In one study, for example, Yehuda Elkana examined the historical meaning of the word energy to explore its role in the discovery of conservation of energy (1974); as Charles Bazerman points out, Elkana "notes the confusion in terminology that prevented the discovery of conservation of energy until appropriate terminology lent precision to the concept of energy" (1983, p.156-84). Practitioners themselves are sometimes cognizant of the role terminology can play in effective communication of novel ideas. For example, in the 1940s, Selman Waksman deliberately chose the term antibiotic for indexing purposes to describe the compounds being developed at the time. Originally, a 19th-century adjective meaning simply "against life," the term was no longer current for most doctors, and so Waksman resurrected it in a new sense: "compounds produced by microbes which have an injurious effect on the growth of other microbes." Subsequently, antibiotic began to appear in such publications as Biological Abstracts (1973).

But while these examples offer insights into the process of scientific 
communication, they do not examine in detail readers' actual responses to the use of technical or scientific terms. Such an examination would be helpful for technical communicators in considering the impact that the use of confusing terminology can have in the reception of their writing. This paper therefore addresses the issue of ambiguity and confused terminology in technical communication by examining a historical technical example the only one found to offer detailed discussion by practitioners in the scientific literature. Specifically, it shows how bypassing can contribute to the slow uptake of an idea. While the example is a medical one-the use of the term antiseptics-it is also technical, and it involves instruction for performing a task. Readers often misunderstood these instructions and did not follow them properly because of bypassing.

\section{Antiseptics and Joseph Lister}

Antiseptic is defined today simply as "1. preventing sepsis. 2. a substance that inhibits the growth and development of microorganisms, but does not necessarily kill them" (Dorlands, 1977). Antisepsis refers to a process or treatment, and stems from the Greek anti-, "against," and sepsis, "putrefaction." The word was in use from 1712 (Skinner, 1961; Haubrich, 1984), and so it was a familiar medical term to doctors. But its meaning did not involve the notion of germs, which were not yet understood as the cause of infectious disease.

A review of early medical dictionaries will help to clarify this earlier use. In 1809, the London Medical Dictionary by Bartholomew Parr discussed antiseptics as important for preventing putrefaction. Prevention was necessary since decay of the body would naturally lead to death; antiseptics, then, were those important medicines that resisted or corrected putrefaction, including stimulants (wine, alcohol, spices), tonics (camomile), antispasmodics (camphor), and dietetics. In 1854, Alexander Macaulay defined antiseptics more completely in his Dictionary of Medicine Designed for Popular Use as substances such as sea salt, sugar, vinegar, bark, and hops that prevented animal and vegetable matter from putrefying. He indicated that "putrescency" is characteristic of several diseases as well as bodily conditions; antiseptics, then, were taken internally for certain ailments, as well as applied externally to wounds. For example, Macaulay noted the "true antiseptic" for sea scurvy, a disease "of so putrescent a nature," is lemon juice or vegetables.

In addition to these two British dictionaries, American sources also referred to antiseptics and putrefaction in similar fashion. For example, in 1860 
Robley Dunglison briefly listed a diverse range of compounds as the main antiseptics used both internally and externally, including muriatic acid, nitric acid, and sulfuric acid.

These sources hint at the medical conception of the disease process before the germ theory of disease. Up to the mid-1800s, doctors generally believed that some gaseous component of air caused decay and that small particles in it (germs) were incidental. But in 1867, the British surgeon Joseph Lister (1827-1912), following the recent researches of Louis Pasteur, noted that it was the "minute particles suspended" in air that caused decomposition, or putrefaction (Cameron et al., 1909, p.2). His view of germs as the cause and not the effect of putrefaction showed a fundamental shift in thinking not only about germs, but about the nature and purpose of antiseptics, those substances used in the treatment of wounds and diseases. Lister suggested that physicians therefore need "to dress the wound with some material capable of killing these septic germs"(p.3). For him, carbolic acid was reliable for this purpose, and he continually modified its use from applying simple carbolic acid-soaked dressings to refinements such as spraying carbolic acid in the air around the patient. Lister valled his technique the antiseptic system of treatment.

Given their familiarity with the term antiseptic, many readers of Lister's publications could not see that he was describing anything new; what was different was his method of its use together with his explanation of the process of putrefaction. As explained more fully by his nephew Richman J. Godlee, Lister's treatment depended upon "certain postulates, the appreciation and acceptance of which are essential to its successful application" (Quain, 1895, p.86). The postulates were that septic processes in a wound are caused by development in it of minute living organisms; that these organisms were introduced from outside (for instance, from the hands of the operator); and that there were means to kill these organisms. These premises, which underpin the germ theory of disease, were so revolutionary in 1867 that Lister had first to acquaint and then convince others of their worth before he could persuade them to implement his system of surgical treatment. His efforts to explain both were not always successful. Compounding any possible confusion resulting from Lister's poor writing (Fisher, 1977), was his use of the term antiseptics, for in effect he adopted a well-entrenched medical expression and used it in a new context, an act which seems to guarantee bypassing.

Thus his audience read about his new antiseptic treatment to kill germs with the former meaning of "preventing putrefaction." Lister perhaps realized 
his mistake in using this word soon after publishing, for he attempted in 1868 to clarify what he meant by antiseptic:

In speaking of the antiseptic system of treatment, I refer to the systematic employment of some antiseptic substance, so as to entirely prevent the occurrence of putrefaction in the part concerned, as distinguished from the mere use of such an agent as a dressing. The latter has long been practised in many parts of the world. The former originated rather more than three years ago in this city (Glasgow). (Cameron et al., 1909. p.51)

Confusion and misunderstanding about antiseptic surgery-or Listerism as it came to be called-was widespread. However, an actual case study of the initial response to Lister's idea exists in Canada, where the main audience for Lister's work consisted of those who learned only through the written word, as published in their primary means of communication, the medical journal. This case study provides a unique opportunity for technical communicators to examine practitioners' (or users' in today's parlance) understanding of terminology, particularly their attempts to come to terms with new and confusing uses of technical terms.

\section{Antiseptics, Antiseptic Surgery and Canadian Doctors}

Although doctors in Britain had the option of visiting Lister's wards to see his technique at first hand, early attempts to follow his technique in Canada had to rely solely on the written word. An early case (circa 1869) shows what could happen when procedures were tried based on reading alone.

At this time, the antiseptic treatment by means of Carbolic Acid had come in and from Edinburgh had come reports of most extraordinary successes ... [One of the attending physicians] determined to use it according to what he had read. So the wound was covered with Carbolic Oil and Lint etc., bandaged, and there the thing ought to have rested. [italics added]

Then another physician took over:

... but having the Carbolic Oil at hand, he thought he ought to apply it 
frequently-and so he did liberally. There was some misunderstanding about this. Anyhow the treatment was very disappointing-made things worse instead of better .... (McKechnie, 1972)

This case, among other cases which could be cited, shows part of the initial Canadian response to Lister's system, a response marked by confusion over its underlying principles. Confusion in Canada over the new system resolved itself into three groups: doctors who believed in the germ theory of disease and who used carbolic acid to combat the cause of putrefaction, that is, disease germs; doctors who did not believe in the germ theory, but who used carbolic acid to combat the effects of putrefaction, that is, rotting flesh; and doctors who believed they practiced antiseptic surgery as prescribed by Lister, but who in fact had misconstrued his writings and merely used carbolic acid as an external lotion. Many, if not all, used the term antiseptics, but few understood its different meanings. True followers of Lister, however, did acquire some first-hand information from a few Canadian practitioners who visited his wards in Britain and reported back on what they had seen, both formally through the journals, and informally to friends (Howell, 1984; Roland, 1967; Connor, 1967). Even as early as 1868-69, a Canadian physician, Archibald Malloch, wrote at first hand from Scotland, where he was employed as Lister's house surgeon. His article, based on his own experience, outlined the antiseptic procedure in detail and offered Canadian readers the best account by then of Lister's surgical protocol (1868-69).

In the following years, doctors discussed the merits and drawbacks of Lister's system from their own perspective in the pages of the medical journals and at society meetings. The most vocal and persistent opponent to Lister's system was William Canniff of Ontario, who perhaps exemplified the stance of other skeptical doctors. For Canniff, putrefaction was caused by internal chemical changes, not by external harmful germs. He believed that frequent washing and nature itself work to heal wounds; antiseptic lotions aided the natural healing process as they always had by purifying tissue, not by killing unseen harmful germs. In effect, for Canniff, antisepsis consisted of simple cleanliness (Connor, 1967). This view was reiterated years later, in 1889, by Canadian doctors at the annual meeting of the Nova Scotia Medical Society. At least one doctor present, however, "took exception to the statement that antisepsis consisted merely in cleanliness," for he felt wounds needed to be made "surgically clean" by destroying germs (Maritime Medical News, 1889). 
After a series of articles on the merits and uses of carbolic acid in which Canniff argued his point with Archibald Malloch, the only true Listerian in Canada at the time, Canniff admitted in 1879 that he had "been in the habit of injecting some antiseptic" into a wound. His use, however, was consistent with earlier medical practice: "to act chemically upon the devitalized tissue in the same manner as common salt will prevent or arrest decomposition of animal flesh" ("Treatment of Chronic Abscess," 1879).

In the same year, Canniff attempted to clarify his understanding of the term more specifically by differentiating between "true antiseptic surgery" and "Listerism" because "Listerism and Antisepticism are not convertible terms by any means, although very many think they are" ("Antiseptic Surgery 'Listerism,"' 1879). Treatment which prevents "septic poisoning of the system," and the agents that accomplish that end were, Canniff wrote, "justly called antiseptics." Listerism, on the other hand, was based on the premise that air was laden with germs that caused decay. In 1880 he explained his distinction again; responding to a report that he had "confidence in antiseptic surgery," Canniff wrote:

This is quite true; but to the casual reader it might be regarded as endorsing Listerism. Nothing could be more opposite to my conviction and belief, in fact, my knowledge ... Listerism disports itself in the robes of antisepticism.

He repeated his definition of antiseptic treatment as "rest, ventilation, and cleanliness" ("Antiseptic Surgery").

This letter prompted a debate in the pages of the medical press. One doctor took issue with Canniff's portrayal of Lister's technique; to which Canniff replied that he "desired to express as briefly and concisely as possible wherein I thought the two [antiseptic surgery and Listerism] were different" (Canada Lancet, 1881).

Such lively exchanges in the medical literature illustrate problems with communication of Lister's technique. Its underlying theory, although new to most readers, who may have been antagonized toward it, was inappropriately tied to the old perception of surgical treatment through the use of the same word: antiseptics. By adopting this word to explain a new system grounded in a new theory, Lister simply confused, frustrated, and perhaps even alarmed some of his readers who, familiar with the former meaning, could not make the intellectual leap Lister's system demanded of them. His meaning was by- 
passed in the mind of the reader.

\section{Discussion}

Although opponents might not have readily accepted the germ theory of disease as true, they might at least have been more willing to suspend quick judgment if Joseph Lister had coined a new term to explain a new procedure based on a new theory. For example, he could simply have chosen the word aseptic, which means "without putrefaction"; ironically, this is what he was attempting to achieve all the while, and antiseptic surgery evolved into aseptic surgery by the end of the 19th century. By using antisepsis, he called attention to the means-carbolic acid- rather than to the result (Fisher, 1977). Unfortunately, he never recognized this and disliked both the term aseptic and the use of aseptic in reference to surgery (Fisher).

Perhaps Lister could also have chosen a less familiar term and applied it to his new context, just as Waksman did in more recent times with the word antibiotic. Indeed, had Lister thought more carefully, he himself might have used the word antibiotic, which more closely conveys the theory he espoused (against the life of germs, rather than against decomposition). One obvious implication of this historical study for modern technical communicators, then, is its reinforcement of the currently recognized need to write from the reader's perspective and not from the writer's. Greater sensitivity to audience needs in the ways suggested might have made Lister's writings more persuasive.

This historical study also has other implications for technical communicators at a higher level of generalization. Thomas Kuhn has shown that during revolutionary periods in science (in Kuhn's words paradigm shifts) scientific practitioners of competing paradigms practice in different worlds: "the two groups of scientists see different things when they look from the same point in the same direction" (1970, p.150). As Bazerman has noted, if Kuhn is correct, then "at the height of revolution . . . there should be clear evidence of miscommunication between members of the two matrices [paradigms]" (1983). This study of antiseptics provides clear evidence of such miscommunication: medical practitioners Malloch and Canniff in particular argued through each other, not against each other, owing to Lister's confusing use of a term each thought he understood. Meanings were bypassed as his term masked deeper conceptual frameworks for its use.

Discussion of this point raises the larger issue of the social context for scientific writing and, indeed, of the changing paradigm of medicine in the 
19 th century. We have dealt with only one aspect here to illustrate how a fundamental problem with language use can impede the uptake of a new idea. It is during such times of changing paradigms that the technical communicator runs the highest risk of having information misinterpreted. Assuming that most technical communicators perform a mediating role between originators of technical information and an intended audience, based on this historical study and in keeping with current trends in the field of information development (Lillies, 1987), we would suggest that technical communicators be more involved in the developmental stages of an idea. This involvement is especially important when technical communicators determine that an originator's information is particularly novel or even revolutionary in nature. Writers should then choose terms with exaggerated care, ensuring that they do not adopt either a well-entrenched term to describe a new concept or a new term for something known. Approaches used today, of course, involve terminology experts and product developers working together to establish mutually agreeable definitions of terms, and the compilation of in-house glossaries for consistency in use of the terms (Olsen, 1984).

Such awareness is crucial; for as we have seen, Lister's use of an old term in a new way often led to simple bypassing. To say that bypassing alone kept doctors from trying Lister's treatment would be an overstatement, and so we are currently preparing a larger study on Lister's works to examine more facets of the problem. Nevertheless, this semantic barrier certainly did not help. Doctors became confounded over the whole issue of antiseptics, and it took a generation 30 years for most to accept Lister's system.

\section{References}

Bazerman, C. (1983). Scientific writing as a social act: A review of the literature of the sociology of science. New Essays in Technical and Scientific Communication: Research, Theory, Practice. Paul V.Anderson et al. eds. Farmingdale, NY: Baywood Publishing, 156-184.

Butler, D. (1986). The function of metaphor in technical discourse. Journal of Technical Writing and Communication, 16 (1/2), 141-146.

Cameron, H.C. et al. Eds. (1909). The Collected Papers of Joseph, Baron Lister, 2. Oxford: Claredon Press.

Canniff, W. (1879). Antiseptic surgery-'Listerism'. Canada Lancet 12, 6570. 
Canniff, W. (1880). Antiseptic surgery vs. Listerism. Canada Medical Record 9, 9.

Canniff, W. (1879). Treatment of chronic abscess. Canada Lancet, 11, 292-293.

Chisholm, R.M. (1986). Selecting metaphoric terminology for the computer industry. Journal of Technical Writing and Communication, 16 (3), 195220.

Connor, J.T.H. (1980). Joseph Lister's System of Wound Management and the Canadian Medical Practitioner, 1867-1900.Unpublished M.A. thesis. University of Western Ontario.

Dorland's Pocket Medical Dictionary (22nd ed.). (1977). Philadelphia: W.B.Saunders.

Dunglison, R. (1860). A Dictionary of Medical Science (revised ed.). Philadelphia: Blanchard and Lea.

Elkana, Y. (1974) The Discovery of the Conservation of Energy. Cambridge: Harvard University Press, 22-51.

Empson, W. (1961). Seven Types of Ambiguity. Harmondsworth: Penguin.

Fisher, R.B. (1977). Joseph Lister 1827-1912. London: MacDonald and Jane's, 146-147.

Haney, W.V. (1979). Communication and Interpersonal Relations (4th ed.). Homewood, IL: Richard D. Irwin.

Haubrich, W.S. (1984). Medical Meanings: A Glossary of Word Origins. San Diego: Harcourt Brace Jovanovich.

Hayakawa, S. (1972). Language in Thought and Action (3rd ed.). New York: Harcourt Brace Jovanovich, 230.

Howell, C.D. (1984). Elite doctors and the development of scientific medicine: The Halifax medical establishment and 19th century medical professionalism. Health, Disease, and Medicine: Essays in Canadian History. Charles G. Roland Ed. Toronto: Hannah Institute for the History of Medicine, 105-122.

Hunt, P., \& Kirkman, J. (1986) The problems of distorted English in computer documentation. Technical Communication, 33 (3), 150-156. 
Korzybski, A. (1958). Science and Sanity (4th ed.). Lakeville, CN: International Non-Aristotelian Library Publishing.

Kuhn, T.S. (1970). The Structure of Scientific Revolutions (2nd ed.). Chicago: University of Chicago, 150.

Lee, I.J. (1982). Why discussions go astray. Readings in Business Communication (3rd ed.). Robert D.Gieselman Ed. Champaign, IL: Stipes Publishing, 15-26.

Letters to the editor. (1881). Canada Lancet 13, 137-138; 201-202.

Lewis, P.V. (1980). Organizational Communication: The Essence of Effective Management (2nd ed.). Columbus, $\mathrm{OH}$ : Grid Publishing.

Lillies, P. (1987). Producing a manual set in the computer industry. Technostyle 6 , sprg., 10-14.

Macaulay, A. (1854). A Dictionary of Medicine (12th ed.). Edinburgh: Adam and Charles Black.

Malloch, A.E. (1868-1869). Case of unusually large loose cartilage in the knee-joint. Dominion Medical Journal, 1, 104-106.

McKechnie, R.E. (1972). Strong Medicine. Vancouver: J.J.Douglas, 117-118.

Olsen, M.E. (1984). Terminology in the computer industry: Wading through the slough of despond. IBM Technical Report Number 07.793: Writing in Response to a Changing Environment. Rochester, MN: System Products Division, 95-108.

Parr, B. (1809) London Medical Dictionary, 1. London.

Quain, R. Ed. (1895). A Dictionary of Medicine, I. New York: D.Appleton, 86.

Roland, C.G. (1967). The early years of antiseptic surgery in Canada. Journal of the History of Medicine and Allied Sciences 22, 380-391.

Skinner, H.A. (1961). Dictionary of Medical Terms (2nd ed.). London: Williams and Wilkins.

The 1889 annual meeting of the Nova Scotia Medical Society. (1889). Maritime Medical News, 1, 107-112.

Waksman, S.A. (1973). History of the word "antibiotic." Journal of the History of Medicine and Allied Sciences, 28, 284-286.

Weeks, F.W., Jameson, D.A., \& Gieselman, R.D. (1984). Principles of Business Communication (3rd ed.). Champaign, IL: Stipes Publishing. 
